\title{
Repeated thermo-hydrolytic disintegration of medium density fibreboards (MDF) for the production of new MDF
}

\author{
Fahriye Yağmur Bütün Buschalsky ${ }^{1}$. Carsten Mai ${ }^{1}$
}

Received: 21 January 2021 / Accepted: 26 July 2021 / Published online: 9 August 2021

(c) The Author(s) 2021

\begin{abstract}
Medium density fibreboards (MDF) are currently not recycled after service life, but various publications report on recycling by the disintegration of MDF using various techniques and the properties of obtained recovered fibres (RF). In this study, the main aim was to put back RF into the MDF manufacturing process as closed-loop recycling using repeated thermo-hydrolytic disintegration. Compared to previous studies, the focus was on the recycling of MDF with a relatively low F:U molar ratio (1.11). Urea-formaldehyde-bonded MDF with a target density of $700 \mathrm{~kg} \mathrm{~m}^{-3}$ was subjected to thermo-hydrolytic disintegration in an autoclave using only water at $95^{\circ} \mathrm{C}$ for 20-30 min. Afterwards, the properties of RF and virgin fibres (VF), of MDF produced thereof and the composition of the disintegration water (DW) were determined. The nitrogen content (NC) revealed that RF contained about $30 \%$ of the initially applied UF. The $\mathrm{pH}$ of the DW hardly changed during recycling and it contained considerable amounts of reducing sugars. Using RF did not result in higher formaldehyde emissions than VF. Compared to earlier studies using a higher formaldehyde content (higher F:U ratio), MDF bonded with modern UF resins can be disintegrated under clearly milder disintegration conditions with respect to temperature and time. The properties of recycled MDF were similar to those of reference MDF; up to $100 \%$ RF could be used without severely deteriorating the strength and increasing formaldehyde emissions from these panels.
\end{abstract}

\section{Introduction}

Medium density fibreboard (MDF) is a dry formed engineered wood product composed of fine lignocellulosic fibres, combined with a synthetic resin and joined under heat and pressure (Thoemen et al. 2010). MDF is used in a wide range of applications mainly for flooring, but also for construction and furniture. It has substituted solid timber as well as other wood-based panels (WBP), due to its availability and wide range of thicknesses and the ability to be machined and finished to a high standard (WPIF 2014). Thus, fibreboard production in Europe encompasses mainly MDF, which makes up about $70 \%$ of the fibreboard market in Europe (Mantanis et al. 2018). Global MDF production, on the other hand, together with high density fibreboard has reached 98.6 million $\mathrm{m}^{3}$ in 2018 (FAO 2019). After service life, these panels will eventually become waste that is deposited in landfills

Fahriye Yağmur Bütün Buschalsky

ybuetue@gwdg.de

1 Department of Wood Biology and Wood Products, GeorgAugust-Universität, Büsgenweg 4, 37077 Göttingen, Germany or burned (Irle et al. 2018). Incineration of waste MDF for energy production, in the form of heat rather than electricity, is used as a waste disposal option (Mitchell and Stevens 2009). Even though the word "waste" projects a perception of a material with no value or useful purpose (Rowell et al. 1991), these panels and production residues can be disintegrated using various techniques and the obtained recovered fibres (RF) can be utilized as an alternative wood source for further material production such as MDF.

Hitherto, three types of techniques have been developed for disintegrating thermosetting resin-containing WBP. These include mechanical, thermo-hydrolytic and chemicalassisted disintegration techniques. The thermo-hydrolytic disintegration technique is viable for WBP that are bonded with hydrolysable resins (such as urea-formaldehyde-UF). After crushing the material, liquid water and/or steam at high temperature and pressure causes hydrolytic cleavage of resin bonds in WBP (Kharazipour and Kües 2007). Thus, the process detaches the wood particles (or fibres) constituting roughly $90 \%$ of the WBP, which can thus be further processed.

Thermo-hydrolytic disintegration of MDF may alter the properties of the wood fibres, which are designated as 
recovered fibres (RF) after this process. Changed fibre morphology (e.g. aspect ratio), chemical nature of the fibres and residual resin might influence panel properties such as strength, water uptake and thickness swelling (Benthien et al. 2017). Therefore, utilising RF for new MDF production can affect the physico-mechanical and chemical properties of the panels. It was recently shown that $10 \%$ recovered fibres obtained from offcuts and trims of high density fibreboard (HDF) can be added to virgin fibres to produce industrial HDF, which meets the related standard requirements (Sala et al. 2020). On the other hand, the disintegration water (DW), which is removed after the thermo-hydrolytic disintegration process, contains a certain amount of hydrolysed UF resin and most likely some degraded wood components. Only two previous studies (Hagel and Saake 2020; Lubis et al. 2018a) related to thermo-hydrolytic disintegration of WBP have investigated the DW. Knowing the chemical composition of the DW is especially important to balance the process streams and to pursue wastewater management.

Previous studies about waste WBP disintegration have dealt with panels containing UF resins with a higher formaldehyde content (higher formaldehyde to urea molar ratio) than nowadays. However, in the late $80 \mathrm{~s}$, resin manufacturers turned towards decreasing the F:U molar ratio in order to reduce formaldehyde emission (Markessini 1994). Thus, the results of more previous studies are based upon data between 2001 and 2010. In addition, most studies in this field have only focused on a single disintegration cycle. This study assesses the recyclability of MDF with lower F:U molar ratio. RF obtained from thermo-hydrolytic disintegration of uncoated MDF were put back into the MDF manufacturing process as a closed loop recycling. The main aim was to investigate the effects of using RF on the properties of newly produced MDF after repeated thermo-hydrolytic disintegration processes. Furthermore, the study examines the chemical properties (nitrogen, formaldehyde, $\mathrm{pH}$ ) of the RF compared to virgin fibres (VF) and relates it to the properties of the respective DW.

\section{Material and methods}

\subsection{Production of the first-generation MDF panels}

Virgin fibres (VF) of 90\% Scots pine (Pinus sylvestris) and $10 \%$ radiata pine (Pinus radiata) were obtained from Steico SE (Feldkirchen, Germany). Prior to resinating, fibres were loosened in a hammer mill (VS1 N, Electra SAS, Poudenas, France) using $2.0 \mathrm{~mm}$ mesh size. A proportion of $10 \%$ (dry mass of resin) commercial liquid urea-formaldehyde (UF) resin (Kaurit 350, BASF, Ludwigshafen, Germany) based on dry fibre mass and $2 \%$ ammonium sulphate $\left(\left(\mathrm{NH}_{4}\right)_{2} \mathrm{SO}_{4}\right)$ based on the resin solid content as hardener were sprayed onto the fibres in a drum blender with rotating speed at 50 rounds $\mathrm{min}^{-1}$. After resinating, the fibres were once again loosened in the aforementioned hammer mill with the same mesh size. Subsequently, fibre mats were manually formed using a $450 \times 450 \mathrm{~mm}^{2}$ forming box on an aluminium plate covered with siliconized paper and pre-pressed. A siliconized paper and a second aluminium plate were laid on the pre-pressed mat for pressing the panels under heat $\left(190{ }^{\circ} \mathrm{C}\right)$ and pressure $\left(5 \mathrm{~N} \mathrm{~mm}^{-2}\right)$ to a target density of $700 \mathrm{~kg} \mathrm{~m}^{-3}$ to reach a panel thickness of either $10 \mathrm{~mm}$ or $16 \mathrm{~mm}$ using metal bar stops. The pressing time amounted to $15 \mathrm{~s} \mathrm{~mm}^{-1}$. A total of $15 \mathrm{MDF}$ panels were produced for each targeted thickness (Table 1). After a day of cooling down and subsequent trimming the edges of the panels to $400 \times 400 \mathrm{~mm}^{2}$, the panels were cut to dimensions depending on further processing and stored in a climate chamber at $20^{\circ} \mathrm{C}$ with $65 \%$ relative humidity until they reached a constant mass.

Table 1 Production of the MDF panels throughout the different generations

\begin{tabular}{|c|c|c|c|}
\hline MDF generation and thickness & Used fibre type & $\begin{array}{l}\text { Number of pro- } \\
\text { duced MDF }\end{array}$ & $\begin{array}{l}\text { Number of produced } \\
\text { reference-MDF using } \\
\text { virgin fibres }\end{array}$ \\
\hline 1st generation, $10 \mathrm{~mm}$ & Virgin fibres & 15 & - \\
\hline 1st generation, $16 \mathrm{~mm}$ & Virgin fibres & 15 & - \\
\hline 2nd generation, $10 \mathrm{~mm}$ & $\begin{array}{l}\mathrm{RF} \text { from thermo-hydrolytic disintegration of } 10 \mathrm{~mm} \\
\text { 1st generation MDF }\end{array}$ & 8 & 2 \\
\hline 2nd generation, $16 \mathrm{~mm}$ & $\begin{array}{l}\mathrm{RF} \text { from thermo-hydrolytic disintegration of } 16 \mathrm{~mm} \\
\text { 1st generation MDF }\end{array}$ & 9 & 3 \\
\hline 3rd generation, $10 \mathrm{~mm}$ & $\begin{array}{l}\mathrm{RF} \text { from thermo-hydrolytic disintegration of } 10 \mathrm{~mm} \\
\text { 2nd generation MDF }\end{array}$ & 5 & 3 \\
\hline 3rd generation, $16 \mathrm{~mm}$ & $\begin{array}{l}\mathrm{RF} \text { from thermo-hydrolytic disintegration of } 16 \mathrm{~mm} \\
\text { 2nd generation MDF }\end{array}$ & 6 & 3 \\
\hline
\end{tabular}




\subsection{Thermo-hydrolytic disintegration of MDF panels}

For each disintegration run, pieces cut from first or subsequent generation MDF with $50 \times 50 \mathrm{~mm}^{2}$ in cross-section were immersed in water at $95{ }^{\circ} \mathrm{C}$ in the autoclave Zirbus Z3 (Zirbus Technology GmbH, Bad Grund, Germany) for a certain duration depending on the board thickness (Table 2). After removing the excess water (so-called disintegration water-DW) using a centrifuge device (a spin-dryer for laundry 776 SEK, Robert-Thomas GmbH, Neunkirchen, Germany) recovered fibres (RF1, RF2, the number denotes the recycling runs) were dried to 5\% moisture content at $70{ }^{\circ} \mathrm{C}$ in a drying-oven. From this, it can be reasonably assumed that each kilo of RF material absorbed ca. $2 \mathrm{~L}$ of the disintegration water.

\subsection{Production of the second- and third-generation MDF panels}

Second- and third-generation MDF were produced using RF from thermo-hydrolytic disintegration of the previous generation MDF. The production process, methods, materials and their amounts were kept identical to the previous MDF generation. Second-generation MDF of $10 \mathrm{~mm}$ thickness were produced using RF1 obtained from thermo-hydrolytic disintegration of $10 \mathrm{~mm}$ first-generation $\mathrm{MDF}$ - equivalently for $16 \mathrm{~mm}$ second-generation MDF and the following recycling run (Table 1). A total of 8 (10 mm thickness) and 9
(16 mm thickness) MDF panels were produced. In parallel, 2 (10 mm thickness) and 3 (16 mm thickness) reference-MDF panels were produced from virgin fibres. The total numbers of third-generation MDF panels using RF2 were $5(10 \mathrm{~mm}$ thickness) and 6 (16 mm thickness). In addition to the recycled third-generation MDF, 3 reference-MDF panels were produced for each targeted thickness using virgin fibres.

\subsection{Chemical properties of the VF and RF}

The $\mathrm{pH}$ value was measured after cold-water extraction of the fibres using two replicas; $2 \mathrm{~g}$ of sample material was placed into a $100 \mathrm{ml}$ Erlenmeyer flask and $60 \mathrm{ml}$ of distilled water was added. Afterwards, the Erlenmeyer flask was placed on a shaker at room temperature; the measurements were taken after $20 \mathrm{~min}, 4 \mathrm{~h}$ and $24 \mathrm{~h}$ with a $\mathrm{pH}$ electrode InoLab Level 2 (WTW GmbH, Weilheim, Germany). Formaldehyde emission from the fibre mass was determined based on the basic principle of the standard EN 717-3 (1996) using approximately $2 \mathrm{~g}$ of fibre material in a bleached tea bag after $3 \mathrm{~h}$ and $24 \mathrm{~h}$ emission. NC was determined using the Kjeldahl method as described previously (Bütün et al. 2019) in order to assess the remaining resin content on the RF after thermo-hydrolytic disintegration. Calculation of UF content assumed that the UF resin contains roughly $30 \%$ of nitrogen. Morphological characterization of the RF and comparison with virgin fibres were separately studied (F.Y.B.B., unpublished data 2020).
Table 2 Thermo-hydrolytic disintegration process parameters of the MDF panels throughout the different generations

\begin{tabular}{|c|c|c|c|c|}
\hline $\begin{array}{l}\text { Thermo-hydrolytic } \\
\text { disintegration run }\end{array}$ & Disintegrated MDF panel & $\begin{array}{l}\text { Amount of disinte- } \\
\text { grated MDF }(\mathrm{kg})\end{array}$ & $\begin{array}{l}\text { Amount of water } \\
\text { at } 95^{\circ} \mathrm{C} \text { (l) }\end{array}$ & $\begin{array}{l}\text { Dura- } \\
\text { tion } \\
(\mathrm{min})\end{array}$ \\
\hline A & 1st generation, $10 \mathrm{~mm}$ & 4 & 28 & 20 \\
\hline B & 1st generation, $10 \mathrm{~mm}$ & 4 & 28 & 20 \\
\hline $\mathrm{C}$ & 1st generation, $10 \mathrm{~mm}$ & 4 & 28 & 20 \\
\hline $\mathrm{D}$ & 1st generation, $10 \mathrm{~mm}$ & 4 & 28 & 20 \\
\hline $\mathrm{E}$ & 1st generation, $10 \mathrm{~mm}$ & 4 & 28 & 20 \\
\hline $\mathrm{F}$ & 1st generation, $16 \mathrm{~mm}$ & 5 & 32 & 30 \\
\hline G & 1st generation, $16 \mathrm{~mm}$ & 5 & 32 & 30 \\
\hline $\mathrm{H}$ & 1st generation, $16 \mathrm{~mm}$ & 5 & 32 & 30 \\
\hline I & 1st generation, $16 \mathrm{~mm}$ & 5 & 32 & 30 \\
\hline $\mathrm{J}$ & 1st generation, $16 \mathrm{~mm}$ & 5 & 32 & 30 \\
\hline K & 1st generation, $16 \mathrm{~mm}$ & 5 & 32 & 30 \\
\hline $\mathrm{L}$ & 2nd generation, $10 \mathrm{~mm}$ & 4 & 28 & 20 \\
\hline M & 2nd generation, $10 \mathrm{~mm}$ & 4 & 28 & 20 \\
\hline $\mathrm{N}$ & 2nd generation, $10 \mathrm{~mm}$ & 1.5 & 10.5 & 20 \\
\hline $\mathrm{O}$ & 2nd generation, $16 \mathrm{~mm}$ & 5 & 32 & 30 \\
\hline $\mathrm{P}$ & 2nd generation, $16 \mathrm{~mm}$ & 5 & 32 & 30 \\
\hline $\mathrm{R}$ & 2nd generation, $16 \mathrm{~mm}$ & 5 & 32 & 30 \\
\hline$S$ & 2nd generation, $16 \mathrm{~mm}$ & 3 & 18 & 30 \\
\hline
\end{tabular}




\subsection{Determination of the physico-mechanical and chemical properties of the MDF panels}

The density of each individually cut MDF specimen was determined according to EN 323 (1993) and the overall density of a panel was calculated as the average of these samples. Moisture content (MC) was determined according to EN 322 (1993) with 12 specimens per panel. Internal bond strength (IB) was determined according to EN 319 (1993) and thickness swelling (TS) and water uptake (WU) after $24 \mathrm{~h}$ immersion in water according to EN 317 (1993) applying sample dimensions of $50 \times 50 \mathrm{x}$ board thickness $\left(\mathrm{mm}^{3}\right)$ with 3 specimens per panel. Flexural strength and modulus of elasticity (MOE) were determined according to EN 310 (1993) applying sample dimension of $250 \times 50 \times 10 \mathrm{~mm}^{3}$ and $370 \times 50 \times 16 \mathrm{~mm}^{3}$ depending on the board thickness with 3 specimens per panel. Formaldehyde emission of the boards was analysed according to EN 120 (1992, perforator method) and EN 717-2 (1995, gas analysis method) with a single specimen per panel and EN 717-3 (1996, flask method) with two specimens per panel for $3 \mathrm{~h}$ and $24 \mathrm{~h}$. Nitrogen content (NC) of the panels was determined using Kjeldahl method as previously described (Bütün et al. 2019). The UF content of the produced MDF panels was calculated considering that the UF resin contains roughly $30 \%$ of nitrogen neglecting the very low $\mathrm{NC}$ of the virgin fibres $(<0.1 \%)$.

\subsection{Chemical analysis of the DW}

Disintegration water (DW) was analysed with respect to the $\mathrm{pH}$ value, formaldehyde content based on acetylacetone method (EN 120 1992), NC based on Kjeldahl method as previously described (Bütün et al. 2019), and the UF content was calculated (considering that the UF resin contains roughly $30 \%$ of nitrogen) for samples after each disintegration run. The amount of reducing sugar equivalents in the DW was assessed based on 3,5-dinitrosalicylic acid (DNSA) method (Miller 1959).

\subsection{Statistical analysis}

Welch's $t$-test was conducted at a level of significance $\alpha=0.05$ to determine the significance of the results among the panels throughout the different generations using Excel 2016 (Microsoft, Redmond, WA, USA). Except for the NC and calculated UF content of the MDF panels and RF, each thickness class was evaluated individually. Second- and third-generation MDF panels were compared to their corresponding first-generation MDF panels and to their reference panels depending on the panel thicknesses.

\section{Results and discussion}

\subsection{Chemical properties of the virgin (VF) and recycled fibres (RF)}

The $\mathrm{pH}$ values of the fibres were measured after three different time spans but the differences for each fibre type were so low that only the average value was reported (Table 3 ). While the $\mathrm{pH}$ value of VF amounted to 4.0, those of $\mathrm{RF}$ were on average 4.9 and 5.2 after each recycling process, respectively. The slightly higher $\mathrm{pH}$ values of the $\mathrm{RF}$ may be due to the formation of ammonia due to the breakdown of the UF-resin, which reacts to alkaline ammonium hydroxide in water (Roffael and Hüster 2012; Wan et al. 2014). Roffael et al. (2009) assumed, that the highly increased $\mathrm{pH}$ value of the RF (6.3) in their study also enhances the cleavage

Table 3 Chemical properties of the virgin fibres (VF) and recovered fibres (RF). Equal letters within a property indicate that there is no statistical difference between the fibre types

\begin{tabular}{|c|c|c|c|c|c|c|c|c|}
\hline Fibre type & & & $\begin{array}{l}\mathrm{pH}(20 \mathrm{~min}, \\
4 \text { and } 24 \mathrm{~h})\end{array}$ & $\begin{array}{l}\text { Formaldehyde } \\
\text { emission- Flask } \\
\text { method (mg/kg } \\
\text { o.d. fibre) }(3 \mathrm{~h})\end{array}$ & $\begin{array}{l}\text { Formaldehyde } \\
\text { emission- Flask } \\
\text { method (mg/kg } \\
\text { o.d. fibre) }(24 \mathrm{~h})\end{array}$ & $\begin{array}{l}\text { Nitrogen } \\
\text { content } \\
(\%)\end{array}$ & $\begin{array}{l}\text { Calculated } \\
\text { UF content } \\
(\%)\end{array}$ & $\begin{array}{l}\text { Amount of } \\
\text { initial UF content } \\
\text { remained on the } \\
\text { fibres }(\%)\end{array}$ \\
\hline \multirow[t]{2}{*}{ Virgin fibres } & Non-milled & & $4.0^{\mathrm{a}}$ & $1.8^{\mathrm{a}}$ & $8.6^{\mathrm{a}}$ & $0.07^{\mathrm{a}}$ & $0.2^{\mathrm{a}}$ & n.a \\
\hline & milled & & $4.0^{\mathrm{a}}$ & $2.0^{\mathrm{a}}$ & $10.0^{\mathrm{a}}$ & $0.07^{\mathrm{a}}$ & $0.2^{\mathrm{a}}$ & n.a \\
\hline \multirow[t]{4}{*}{ RF 1} & $10 \mathrm{~mm}$ & Non-milled & $4.8^{\mathrm{c}}$ & $50.5^{\mathrm{b}}$ & $595.0^{\mathrm{b}}$ & $1.1^{\mathrm{b}}$ & $3.5^{\mathrm{b}}$ & 35.0 \\
\hline & & milled & $4.8^{\mathrm{bc}}$ & $61.3^{\mathrm{b}}$ & $557.0^{\mathrm{b}}$ & $1.0^{\mathrm{b}}$ & $3.2^{\mathrm{b}}$ & 32.0 \\
\hline & $16 \mathrm{~mm}$ & Non-milled & 4.9 & $51.0^{\mathrm{c}}$ & $465^{c}$ & $1.2^{\mathrm{b}}$ & $3.8^{\mathrm{b}}$ & 38.0 \\
\hline & & milled & $5.2^{\mathrm{d}}$ & $62.9^{c}$ & $517.0^{\mathrm{c}}$ & $1.1^{\mathrm{b}}$ & $3.5^{\mathrm{b}}$ & 35.0 \\
\hline \multirow[t]{4}{*}{ RF 2} & $10 \mathrm{~mm}$ & Non-milled & $5.3^{\mathrm{b}}$ & $61.2^{\mathrm{b}}$ & $617^{\mathrm{b}}$ & $2.2^{\mathrm{c}}$ & $7.0^{\mathrm{c}}$ & 51.8 \\
\hline & & milled & 5.0 & $79.5^{\mathrm{b}}$ & $629.0^{\mathrm{b}}$ & $2.5^{\mathrm{c}}$ & $8.0^{\mathrm{c}}$ & 59.2 \\
\hline & $16 \mathrm{~mm}$ & Non-milled & $5.4^{\mathrm{d}}$ & $75.5^{\mathrm{c}}$ & $617.0^{c}$ & $2.2^{\mathrm{c}}$ & $7.0^{\mathrm{c}}$ & 54.6 \\
\hline & & milled & $5.4^{\mathrm{d}}$ & $68.0^{c}$ & $561.0^{\mathrm{c}}$ & $1.9^{\mathrm{c}}$ & $6.1^{\mathrm{c}}$ & 47.6 \\
\hline
\end{tabular}

n.a. = "not applicable" 
of acetyl groups in hemicelluloses and subsequently of the glycosidic bonds.

Formaldehyde emission of the VF after $3 \mathrm{~h}$ was 1.8 and $2.0 \mathrm{mg}$ per $\mathrm{kg}$ oven-dried fibres for non-milled and hammermilled samples, respectively, without significant difference (Table 3). Each recycling process increased the formaldehyde emissions of the RF. In addition, the hammer-milling process further increased the emission, except after hammermilling of second-time recycled RF of $16 \mathrm{~mm}$ panels. The $24 \mathrm{~h}$ formaldehyde emission of non-milled and hammermilled samples VF were again the same resulting in 8.6 and $10.0 \mathrm{mg}$ per kg oven-dried fibres, respectively.

Virgin fibres' NC of $0.07 \%$ is in accordance with Cowling and Merrill (1966), who reported that wood contains approximately $0.1 \%$ nitrogen; Lubis et al. (2018a) found $0.5 \%$ nitrogen in VF. While the NC of the VF was negligibly low, the NC of the RF amounted to approximately $1 \%$ after the first and $2 \%$ after the second disintegration process (Table 3). As the NC of the virgin MDF panels was approximately $3 \%$ (Table 4), this indicates that about $33.5 \%$ of the UF binder remained on the first-generation RF and 53.4\% on the second- generation RF (related to the virgin panels).

\subsection{Physico-mechanical and chemical properties of the MDF panels}

MDF produced from RF exhibited slightly higher densities than the target density and respective reference panels (Table 5). Even though, the IB of the second-generation panels was identical to that of the first-generation and corresponding reference panels. Moreover, the IB of the thirdgeneration $10 \mathrm{~mm}$ MDF panels showed $64.5 \%$ increment (at slight density increase of $3.8 \%$ ), while $16 \mathrm{~mm}$ MDF panels showed $89.5 \%$ increment (the density increased by

Table 4 Chemical properties of virgin and recycled MDF panels. Asterisks and equal letters within a property indicate that there is no statistical difference between the MDF panels throughout the different generations

\begin{tabular}{|c|c|c|c|c|c|c|c|c|}
\hline MDF panels & & & $\begin{array}{l}\text { Formaldehyde } \\
\text { emission-Per- } \\
\text { forator method } \\
\text { (mg/100 g o.d. } \\
\text { board) }\end{array}$ & $\begin{array}{l}\text { Formaldehyde } \\
\text { emission-Gas } \\
\text { analyser method } \\
\left(\mathrm{mg} / \mathrm{m}^{2} \mathrm{~h}\right)\end{array}$ & $\begin{array}{l}\text { Formaldehyde } \\
\text { emission-Flask } \\
\text { method (mg/kg } \\
\text { o.d. board) }(3 \mathrm{~h})\end{array}$ & $\begin{array}{l}\text { Formaldehyde } \\
\text { emission-Flask } \\
\text { method (mg/kg } \\
\text { o.d. board) }(24 \mathrm{~h})\end{array}$ & $\begin{array}{l}\text { Nitrogen } \\
\text { content } \\
(\%)\end{array}$ & $\begin{array}{l}\text { Calculated } \\
\text { UF content } \\
(\%)\end{array}$ \\
\hline \multirow[t]{2}{*}{ 1st generation } & $10 \mathrm{~mm}$ & & 17.2 & $14.8^{\mathrm{a}}$ & $12.2^{\mathrm{a}}$ & $162^{\mathrm{a}}$ & $3.1^{\mathrm{a}}$ & $10.0^{\mathrm{a}}$ \\
\hline & $16 \mathrm{~mm}$ & & 17.7 & $14.5^{\mathrm{d}}$ & $12.0^{\mathrm{c}}$ & $163^{\mathrm{d}}$ & $3.1^{\mathrm{a}}$ & $10.0^{\mathrm{a}}$ \\
\hline \multirow[t]{4}{*}{ 2nd generation } & $10 \mathrm{~mm}$ & Recycled & $15.2^{\mathrm{ad}}$ & 10.9 & $9.3^{\mathrm{b}}$ & $209^{\mathrm{b}}$ & 4.2 & 13.5 \\
\hline & & Reference & $15.1^{\text {ace }}$ & $12.3^{\mathrm{c}}$ & $10.0^{\mathrm{b}}$ & $182^{\mathrm{abc}}$ & $3.2^{\mathrm{a}}$ & $10.4^{\mathrm{a}}$ \\
\hline & $16 \mathrm{~mm}$ & Recycled & $13.7^{\mathrm{f}}$ & $11.2^{\mathrm{e}}$ & $8.8^{\mathrm{d}}$ & $114^{\mathrm{e}}$ & 4.0 & 12.8 \\
\hline & & Reference & 16.2 & $10.9^{\mathrm{e}}$ & $9.6^{\mathrm{de}}$ & $135^{\mathrm{ef}}$ & $3.0^{\mathrm{a}}$ & $9.9^{\mathrm{a}}$ \\
\hline \multirow[t]{4}{*}{ 3rd generation } & $10 \mathrm{~mm}$ & Recycled & $13.4^{\text {be }}$ & $12.9^{\mathrm{bc}}$ & $9.6^{\mathrm{b}}$ & $148^{\mathrm{c}}$ & 5.4 & 17.3 \\
\hline & & Reference & $14^{\mathrm{bcd}}$ & $13.6^{\mathrm{abc}}$ & $13.6^{\mathrm{ab}}$ & $173^{\mathrm{a}}$ & $3.2^{\mathrm{a}}$ & $10.3^{\mathrm{a}}$ \\
\hline & $16 \mathrm{~mm}$ & Recycled & 11.6 & $13.9^{\mathrm{d}}$ & $10.3^{\mathrm{e}}$ & $136^{\mathrm{df}}$ & 4.9 & 15.7 \\
\hline & & Reference & $14.3^{\mathrm{f}}$ & $13.4^{\mathrm{de}}$ & $12.7^{\mathrm{c}}$ & $180^{\text {def }}$ & $3.1^{\mathrm{a}}$ & $9.9^{\mathrm{a}}$ \\
\hline
\end{tabular}

Table 5 Physico-mechanical properties of virgin and recycled MDF panels. Asterisks and equal letters within a property indicate that there is no statistical difference between the MDF panels throughout the different generations

\begin{tabular}{|c|c|c|c|c|c|c|c|c|}
\hline MDF panels & & & Density $\left(\mathrm{kg} / \mathrm{m}^{3}\right)$ & $\begin{array}{l}\text { Internal bond } \\
\text { strength (IB) (N/ } \\
\left.\mathrm{mm}^{2}\right)\end{array}$ & $\begin{array}{l}\text { Flexural } \\
\text { strength (N/ } \\
\left.\mathrm{mm}^{2}\right)\end{array}$ & $\begin{array}{l}\text { Modulus of elastic- } \\
\text { ity }(\mathrm{MOE})(\mathrm{N} / \\
\left.\mathrm{mm}^{2}\right)\end{array}$ & $\begin{array}{l}\text { Water uptake } \\
(\mathrm{WU})(\%) \\
24 \mathrm{~h}\end{array}$ & $\begin{array}{l}\text { Thickness swell- } \\
\text { ing (TS) }(\%) \\
24 \mathrm{~h}\end{array}$ \\
\hline \multirow[t]{2}{*}{ 1st generation } & $10 \mathrm{~mm}$ & & $727^{\mathrm{a}}$ & $0.31^{\mathrm{a}}$ & $30.4 *$ & $2992 *$ & $68.6^{\mathrm{a}}$ & $19^{\mathrm{a}}$ \\
\hline & $16 \mathrm{~mm}$ & & $742^{\mathrm{c}}$ & $0.19^{c}$ & $30.6^{\mathrm{a}}$ & $3310^{\mathrm{a}}$ & $62.6^{\mathrm{c}}$ & $17.3^{\mathrm{d}}$ \\
\hline \multirow[t]{4}{*}{ 2nd generation } & $10 \mathrm{~mm}$ & Recycled & $743^{\mathrm{b}}$ & $0.34^{\mathrm{ab}}$ & $29.6^{*}$ & $3020 *$ & $77.8^{\mathrm{b}}$ & 17.1 \\
\hline & & Reference & $739^{\mathrm{ab}}$ & 0.22 & $32.2 *$ & $3447 *$ & $76.4^{\mathrm{ab}}$ & $20.4^{\mathrm{abc}}$ \\
\hline & $16 \mathrm{~mm}$ & Recycled & $766^{\mathrm{d}}$ & $0.23^{\mathrm{d}}$ & $32.3^{\mathrm{ac}}$ & $3536^{\mathrm{c}}$ & $71.2^{\mathrm{d}}$ & $18.6^{\mathrm{eg}}$ \\
\hline & & Reference & $773^{d}$ & $0.19^{\mathrm{cd}}$ & $34.9^{\mathrm{c}}$ & $4019^{\mathrm{d}}$ & $53.6^{\mathrm{ce}}$ & $16.2^{\mathrm{de}}$ \\
\hline \multirow[t]{4}{*}{ 3rd generation } & $10 \mathrm{~mm}$ & Recycled & $756^{\mathrm{b}}$ & 0.51 & $28.5^{*}$ & $2750 *$ & $73.7^{\mathrm{b}}$ & $19.8^{\mathrm{c}}$ \\
\hline & & Reference & $717^{\mathrm{b}}$ & $0.39^{\mathrm{b}}$ & $28.6^{*}$ & $2974 *$ & $75.6^{\mathrm{ab}}$ & $21.2^{\mathrm{b}}$ \\
\hline & $16 \mathrm{~mm}$ & Recycled & $773^{d}$ & 0.36 & $35.2^{\mathrm{bc}}$ & $3451^{\mathrm{abcd}}$ & $71.5^{\mathrm{d}}$ & $19.5^{\mathrm{f}}$ \\
\hline & & Reference & $747^{\mathrm{c}}$ & $0.20^{\mathrm{cd}}$ & $34^{\mathrm{bc}}$ & $3667^{\mathrm{bc}}$ & $54.2^{\mathrm{e}}$ & $16.8^{\mathrm{dfg}}$ \\
\hline
\end{tabular}


4.0\%) compared to corresponding first-generation panels. In addition to the slightly increased density that may affect IB (Wong et al. 2000; Hong et al. 2017, 2020), the main reason for the higher IB might be the increasing amount of adhesive that remains on the fibres after recycling, as previously reported (Roffael et al. 2002, 2010a; Lykidis and Grigoriou 2008; Bütün et al. 2018, 2019; Lubis et al. 2018b). On the other hand, Roffael et al. (2016) reported that the substitution of VF by $100 \%$ RF decreased the IB of the new MDF significantly. This might be due to strength loss of the recycled fibres and the over proportional consumption of adhesive by fines, which occurs more in recycled MDF. Moreover, a slight reduction in fibre length, which may occur during recycling as reported elsewhere (F.Y.B.B., unpublished data 2020), might explain higher IB. Shorter fibres may result in a larger surface area for enhanced adhesion. In addition, short fibres can strengthen the structure of the MDF by filling the voids between the large fibres, while aligning themselves along the forming direction (Back 1987). Correspondingly, Groom et al. (2002) suggested that there is an optimal ratio of fines (shorter fibres) to larger fibres, where the fines provide a greater degree of bonding. Shortening of fibres, however, reduces flexural strength (Myers 1983; Ye et al. 2007) but a reduction in MOR and MOE was hardly observed (Table 5). On the other hand, flexural strength (MOR) and MOE of recovered MDF panels (10 $\mathrm{mm}$ thickness) were not significantly different despite increasing density (on average 3\% related to first-generation panels) throughout the different generations. Furthermore, repeated recycling of $16 \mathrm{~mm}$ MDF panels resulted in rather fluctuating results in terms of bending strengths, which were not significant and were attributed to fluctuations in the production process. In terms of MOE, $16 \mathrm{~mm}$ MDF showed similar trends except for a 5.8\% decrement for the thirdgeneration panels in comparison to the corresponding reference panels, instead of an increment.

Thickness swelling (TS) of the MDF panels after $24 \mathrm{~h}$ immersion in water progressed differently to the water uptake (WU) (Table 5). The second-generation $10 \mathrm{~mm}$ panels showed $16 \%$ and $10 \%$ reduced TS compared to the corresponding reference and first-generation panels, respectively. TS of third-generation $10 \mathrm{~mm}$ panels was same as the corresponding reference and first-generation panels. Recycled $16 \mathrm{~mm}$ MDF, on the other hand, showed constantly higher TS throughout the generations in comparison to the corresponding reference and first-generation panels. The WU of the MDF after $24 \mathrm{~h}$ immersion did not exhibit significant differences between $10 \mathrm{~mm}$ second- and third-generation panels and their corresponding reference panels, but significantly higher values when compared to the first-generation panels (Table 5). The WU of $16 \mathrm{~mm}$ panels were identical between second- and third-generation panels. The recycled $16 \mathrm{~mm}$ panels showed higher water uptake than the first-generation and the reference panels. Higher WU and TS values of the recycled MDF panels are usually attributed to the poor adhesion of the panels, which can be detected by lower IB. In this study, even though the IB increased throughout the repeated recycling processes, the WU and TS increased after recycling. Moezzipour et al. (2018) assumed the removal of the lignin as a reason; however, this is unlikely for the present study due to neutral $\mathrm{pH}$ value and a relatively moderate temperature during disintegration. A possible reason for higher WU and TS might be the increased availability of hygroscopic low-molecular-weight sugars and of fines, which might act like wicks. In contrast to the present findings, Roffael et al. (2016) observed reduced WU and TS when VF were substituted with $33 \%$ RF. They attributed this improvement to the reactivation of the sizing agent (water repellent) contained in the recycled industrial waste MDF and cross-linking of the RF by free formaldehyde in the UF resin. Virgin panels in the present study, however, did not contain sizing agents. In addition, the higher amount of adhesive in the recovered MDF and the resulting increase in IB might explain the stable water-related properties between the 2 nd and the 3 rd generation of the recycled panels.

Urea, ammonia and oligomeric decay products of UF resin can react with formaldehyde and act as formaldehyde scavengers. Thus, various studies reported significantly reduced formaldehyde content and emission of the recycled MDF (Roffael et al. 2010b; 2016; Behn 2018). Similarly, the formaldehyde emission determined by perforator method of the recycled panels was lower than that of virgin panels throughout the different generations of this study. However, formaldehyde emission results assessed by the gas analysis and flask method did not follow the same trend.

The formaldehyde emission determined by perforator method of the MDF revealed different trends depending on the panel thicknesses (Table 4). Still, regarding both thicknesses, the first-generation panels displayed a significantly higher formaldehyde emission compared to the later generations and their reference panels and the subsequent recycling further decreased the formaldehyde emission of the recycled panels. Recycled $10 \mathrm{~mm}$ panels had an identical formaldehyde emission to their reference panels. However, $16 \mathrm{~mm}$ recycled panels exhibited significantly lower formaldehyde emission of $15.4 \%$ (second-generation) and $18.8 \%$ (third-generation) compared to their corresponding reference panels. Likewise, formaldehyde emission assessed by gas analyser showed different trends depending on the panel thicknesses. Again, the formaldehyde emission of the first-generation panels was significantly higher than that of the subsequent generations and their reference panels. Formaldehyde emissions of both thickness-type panels were lower after the subsequent recycling processes, while that of $10 \mathrm{~mm}$ panels was always lower in comparison to their corresponding reference panels. Panels of $16 \mathrm{~mm}$ thickness 
showed the opposite tendency with slightly but not significantly higher formaldehyde emission values compared to their reference panels.

Formaldehyde emission after $3 \mathrm{~h}$ assessed by the flask method also revealed similar trends to the ones observed by perforator and gas analysis methods; first-generation panels released significantly higher emissions than the subsequent generations and their reference panels. Furthermore, the $10 \mathrm{~mm}$ recycled and respective reference panels displayed identical formaldehyde emission after $3 \mathrm{~h}$. Similarly, $16 \mathrm{~mm}$ recycled panels and second-generation reference panels were identical in terms of $3 \mathrm{~h}$ formaldehyde emission. Reduction in formaldehyde emissions due to recycling is in contrast to increasingly higher emissions of the RF. This might be explained by the fact that the decay products of UF resin (urea, ammonia and oligomers) in the RF material are able to react with formaldehyde and act as formaldehyde scavengers.

Interestingly, the formaldehyde emissions during $24 \mathrm{~h}$ measured by flask method resulted in a different tendency to other related methods. When compared to the first-generation panels, $10 \mathrm{~mm}$ and $16 \mathrm{~mm}$ recycled panels showed unequal trends; emission of $10 \mathrm{~mm}$ second-generation panels was $22.5 \%$ (significantly) higher compared to the firstgeneration panels, while that of third-generation panels was $8.6 \%$ lower. The formaldehyde emission of second-generation $16 \mathrm{~mm}$ panels, however, was $30.1 \%$ and that of thirdgeneration panels $16.5 \%$ lower than the first-generation panels. Both in second and third generations, however, $16 \mathrm{~mm}$ recycled panels were not significantly different from their reference panels. Compared to the previous studies (Dix et al. 2001a, b; Schoo et al. 2003; Roffael et al. 2010a), the rather milder conditions (lower temperature and/or shorter duration) might result in a lower breakdown of the UF resin during the thermo-hydrolytic disintegration. Thus, the slight increment in the formaldehyde emission of the third-generation panels can be due to the higher amount of remaining non-hydrolysed UF-binder, even though, these values were always lower than the first-generation panels, except the $24 \mathrm{~h}$ flask method results for $10 \mathrm{~mm}$ second-generation MDF panels.

The nitrogen content (NC) of the first-generation and reference MDF panels amounted to $3.1 \%$ and indicate that the targeted $10 \%$ UF resin content was reached. NC was determined as an indicator for the UF content of the recycled panels. It exhibited a constant increment after the subsequent recycling processes, while these values were the same for the first-generation and reference panels irrespective of the panel thicknesses. As a result of the remaining UF binder on the RF (33.5\% in RF1 and 53.4\% in RF2), the NC increased by $35.4 \%$ and $74.2 \%$ related to virgin panels for $10 \mathrm{~mm}$ recycled panels and by $29.0 \%$ and $58.0 \%$ for $16 \mathrm{~mm}$ recycled panels after each disintegration process, respectively.

A possible explanation for the inconsistent physicomechanical and fluctuation of chemical results between 10 and $16 \mathrm{~mm}$ panels may be attributed to the natural variability of the wood quality along with the limitations of the laboratory-scale production of them.

\subsection{Chemical characteristics of the disintegration water (DW)}

The $\mathrm{pH}$ values of the DW were increased from 4.5 to 5.1 over the various disintegration runs (Table 6). The formaldehyde content in the DW after the first disintegration process was $249.5 \mathrm{mg} \mathrm{l}^{-1}$ and $342.3 \mathrm{mg} \mathrm{l}^{-1}$ after recycling of the $10 \mathrm{~mm}$ and $16 \mathrm{~mm}$ first-generation panels, respectively. An increment of $11.0 \%$ was observed after the subsequent recycling of the $10 \mathrm{~mm}$ second-generation MDF panels, while $33.4 \%$ decrement occurred after the recycling of the $16 \mathrm{~mm}$ second-generation panels.

Table 6 Chemical properties of the disintegration water (DW) obtained after the disintegration processes compared to the demineralised water

\begin{tabular}{|c|c|c|c|c|c|}
\hline \multirow[t]{3}{*}{ Chemical properties } & \multicolumn{4}{|l|}{ Disintegration water } & \multirow{4}{*}{$\begin{array}{l}\text { Demin- } \\
\text { eralised } \\
\text { water }\end{array}$} \\
\hline & \multicolumn{2}{|c|}{ 1st disintegration process } & \multicolumn{2}{|c|}{ 2nd disintegration process } & \\
\hline & $\begin{array}{l}\text { Runs for } 1 \text { st genera- } \\
\text { tion, } 10 \mathrm{~mm} \text { MDF }\end{array}$ & $\begin{array}{l}\text { Runs for 1st genera- } \\
\text { tion, } 16 \mathrm{~mm} \text { MDF }\end{array}$ & $\begin{array}{l}\text { Runs for } 2 \mathrm{nd} \\
\text { generation, } 10 \mathrm{~mm} \\
\text { MDF }\end{array}$ & $\begin{array}{l}\text { Runs for } 2 \mathrm{nd} \\
\text { generation, } 16 \mathrm{~mm} \\
\text { MDF }\end{array}$ & \\
\hline & $\mathrm{A}, \mathrm{B}, \mathrm{C}, \mathrm{D}, \mathrm{E}$ & $\mathrm{F}, \mathrm{G}, \mathrm{H}, \mathrm{I}, \mathrm{J}, \mathrm{K}$ & $\mathrm{L}, \mathrm{M}, \mathrm{N}$ & $\mathrm{O}, \mathrm{P}, \mathrm{R}, \mathrm{S}$ & \\
\hline $\mathrm{pH}$ & 4.5 & 4.7 & 5.0 & 5.1 & 5.2 \\
\hline Formaldehyde content $\left(\mathrm{mg} \mathrm{l}^{-1}\right)$ & 249.5 & 342.3 & 277.0 & 227.8 & n. a \\
\hline Reducing sugars and equivalents (mg $\mathrm{l}^{-1}$ ) & 7.0 & 6.2 & 0.6 & 0.8 & 0.2 \\
\hline Nitrogen content $(\%)$ & 0.4 & 0.47 & 0.43 & 0.44 & $<0.003$ \\
\hline Calculated UF content (\%) & 1.2 & 1.5 & 1.4 & 1.4 & n. a \\
\hline
\end{tabular}

n.a. = "not analysed" 
Significant levels of reducing sugar equivalents (6-7 mg $\mathrm{l}^{-1}$ ) were detected in the DW after the first disintegration process. These might originate mainly from hemicelluloses, which were cleaved during the production (pulping) of VF or from panel recycling. During these processes, cleavage of acetyl groups may occur followed by cleavage of glycosidic bonds mainly of hemicelluloses. After the second disintegration process, however, the amounts of reducing sugar equivalents in DW were lower than $1 \mathrm{mg} \mathrm{l}^{-1}$ showing $91.4 \%$ and $87.0 \%$ decrement for $10 \mathrm{~mm}$ and $16 \mathrm{~mm}$ panels, respectively (Table 6). This indicates that the first disintegration process already removed most of the extractable sugars. The reason, why the $\mathrm{pH}$ values of the DW obtained after the first disintegration process, is acidic, is that the VF exhibit a pH value of 4.0 (Table 3 ) due to formation of acetic acid during pulping. During the second disintegration process, the $\mathrm{pH}$ values of DW was higher, but still below that of demineralised water.

The NC of the DW obtained after the disintegration of the second-generation $10 \mathrm{~mm}$ panels was slightly higher (7.0\%) than after the previous disintegration. Meanwhile, $16 \mathrm{~mm}$ panels had a slightly lower (6.4\%) NC in DW obtained after the second disintegration. Based on the assumption that each kilo of RF material absorbs ca. $2 \mathrm{~L}$ of water, on average, approximately $65 \%$ and $50 \%$ of the initial UF was found in the DW samples from the 1 st and the 2 nd disintegration process, respectively. The $\mathrm{NC}$ of a specific recycled MDF should be roughly the sum of the $\mathrm{NC}$ of the used $\mathrm{RF}$ and ca. $3.1 \%$ nitrogen, which derives from the $10 \%$ targeted UF resin. The difference between the total $\mathrm{NC}$ of the recycled boards and the NC of DW and RF combined is attributed to evaporation (Hagel and Saake 2020) during draining of the DW and/or during the RF drying.

\section{Conclusion}

The aim of the present study was to assess the recyclability of MDF bonded with current standard UF resins with a relatively low F:U molar ratio using repeated thermo-hydrolytic disintegration. The process required to disintegrate the panels used significantly lower temperatures and was clearly shorter than in previous studies. Even the utilisation of $100 \%$ RF did not bring about significantly lower strength or higher formaldehyde emissions than that of virgin boards. Utilising up to $100 \%$ RF may be an alternative environmentally friendly source for new MDF production. Repeated recycling processes may enhance IB and reduce formaldehyde emissions from the new panels. The thermo-hydrolytic disintegration process alters the chemical properties of the fibres resulting in higher $\mathrm{pH}$ and causes formaldehyde emission from the $\mathrm{RF}$ due to the remaining UF-resin. The initially high amount of reducing sugar equivalents in the DW after the first recycling indicates the cleavage of the hemicelluloses during fibre production (pulping) and/or thermo-hydrolytic recycling.

Funding Open Access funding enabled and organized by Projekt DEAL.

\section{Declarations}

Conflict of interest The authors wish to acknowledge funding by the AiF Projekt GmbH (project No. 16KN065229). We are grateful to Dr. André Klüppel for his valuable suggestions.

Open Access This article is licensed under a Creative Commons Attribution 4.0 International License, which permits use, sharing, adaptation, distribution and reproduction in any medium or format, as long as you give appropriate credit to the original author(s) and the source, provide a link to the Creative Commons licence, and indicate if changes were made. The images or other third party material in this article are included in the article's Creative Commons licence, unless indicated otherwise in a credit line to the material. If material is not included in the article's Creative Commons licence and your intended use is not permitted by statutory regulation or exceeds the permitted use, you will need to obtain permission directly from the copyright holder. To view a copy of this licence, visit http://creativecommons.org/licenses/by/4.0/.

\section{References}

Back EL (1987) The bonding mechanism in hardboard manufacture review report. Holzforschung 41:247-258. https://doi.org/10. 1515/hfsg.1987.41.4.247

Behn C (2018) Recycling of wood fiberboard and particleboard for the production of MDF (Recycling von Holzfaser- und Holzspanplatten für die Herstellung von MDF). In: 5. Fachtagung "Umweltschutz in der Holzwerkstoffindustrie" (5. Conference of "Environmental protection in the wood-based panels industry). Göttingen

Benthien JT, Heldner S, Ohlmeyer M (2017) Investigation of the interrelations between defibration conditions, fiber size and mediumdensity fiberboard (MDF) properties. Eur J Wood Prod 75:215232. https://doi.org/10.1007/s00107-016-1094-2

Bütün FY, Mayer AK, Ostendorf K et al (2018) Recovering fibres from fibreboards for wood polymer composites production. Int Wood Prod J 9:42-49. https://doi.org/10.1080/20426445.2018.1462965

Bütün FY, Sauerbier P, Militz H, Mai C (2019) The effect of fibreboard (MDF) disintegration technique on wood polymer composites (WPC) produced with recovered wood particles. Compos Part Appl Sci Manuf 118:312-316. https://doi.org/10.1016/j.compo sitesa.2019.01.006

Cowling EB, Merrill W (1966) Nitrogen in wood and its role in wood deterioration. Can J Bot 44:1539-1554. https://doi.org/10.1139/ b66-167

Dix B, Schäfer M, Roffael E (2001a) Einsatz von Faserstoffen aus chemisch-thermisch aufgeschlossenen, gebrauchten Faserplatten zur Herstellung von mitteldichten Faserplatten (MDF)-Using fibers from waste fiberboards pulped by a thermo-chemical process to produce MDF. Holz Roh- Werkst 59:276-276. https://doi. org/10.1007/s001070100210

Dix B, Schäfer M, Roffael E (2001b) Einsatz von Faserstoffen aus chemo-thermo-mechanisch (CTMP) aufgeschlossenen, gebrauchten Span- und Faserplatten zur Herstellung von mitteldichten Faserplatten (MDF) - Using fibers from waste particleboards and fiberboards pulped by a chemo-thermo-mechanical 
process to produce MDF. Holz Roh- Werkst 59:299-300. https:// doi.org/10.1007/s001070100211

EN 120 (1992) Wood-based panels-Determination of formaldehyde content; extraction method called the perforator method. German Institute for Standardization

EN 310 (1993) Wood-based panels-Determination of modulus of elasticity in bending and of bending strength. German Institute for Standardization

EN 317 (1993) Particleboards and fibreboards-Determination of swelling in thickness after immersion in water. German Institute for Standardization

EN 319 (1993) Particleboards and fibreboards-Determination of tensile strength perpendicular to the plane of the board. German Institute for Standardization

EN 322 (1993) Wood-based panels-Determination of moisture content. German Institute for Standardization

EN 323 (1993) Wood-based panels-Determination of density. German Institute for Standardization

EN 717-2 (1995) Wood-based panels-Determination of formaldehyde release Part2: formaldehyde release by the gas analysis method. German Institute for Standardization

EN 717-3 (1996) Wood-based panels-Determination of formaldehyde release Part3: formaldehyde release by the flask method. German Institute for Standardization

FAO (2019) Global Forest Products Facts and Figures 2018. FAOFood and Agriculture Organization of the United Nations, Rome

Groom L, So CL, Rials T, et al (2002) Relationships between wood quality, refiner pressure, and resin distribution and their influence on MDF panel properties. In: 6th European Panel Products Symposium. Llandudno, North Wales, UK

Hagel S, Saake B (2020) Fractionation of waste MDF by steam refining. Molecules 25:2165. https://doi.org/10.3390/molecules25092165

Hong M-K, Lubis MAR, Park B-D (2017) Effect of panel density and resin content on properties of medium density fiberboard. Korean Wood Sci Technol 45:444-455. https://doi.org/10.5658/WOOD. 2017.45.4.444

Hong M-K, Lubis MAR, Park B-D et al (2020) Effects of surface laminate type and recycled fiber content on properties of three-layer medium density fiberboard. Wood Mater Sci Eng 15:163-171. https://doi.org/10.1080/17480272.2018.1528479

Irle M, Privat F, Couret L, et al (2018) Advanced recycling of postconsumer solid wood and MDF. Wood Mater Sci Eng 1-5. https:// doi.org/10.1080/17480272.2018.1427144

Kharazipour A, Kües U (2007) Recycling of wood composites and solid wood products. Wood production, wood technology, and biotechnological impacts. Universitätsverlag Göttingen, Göttingen, pp 509-533

Lubis MAR, Hong M-K, Park B-D (2018a) Hydrolytic removal of cured urea-formaldehyde resins in medium-density fiberboard for recycling. J Wood Chem Technol 38:1-14. https://doi.org/10. 1080/02773813.2017.1316741

Lubis MAR, Hong M-K, Park B-D, Lee S-M (2018b) Effects of recycled fiber content on the properties of medium density fiberboard. Eur J Wood Prod 76:1515-1526. https://doi.org/10.1007/ s00107-018-1326-8

Lykidis C, Grigoriou A (2008) Hydrothermal recycling of waste and performance of the recycled wooden particleboards. Waste Manag 28:57-63. https://doi.org/10.1016/j.wasman.2006.11.016

Mantanis GI, Athanassiadou ETh, Barbu MC, Wijnendaele K (2018) Adhesive systems used in the European particleboard, MDF and OSB industries. Wood Mater Sci Eng 13:104-116. https://doi.org/ 10.1080/17480272.2017.1396622

Markessini E (1994) Formaldehyde emissions from wood based panels and wys to reduce them. Monum Environ 2:57-64

Miller GL (1959) Use of dinitrosalicylic acid reagent for determination of reducing sugar. Anal Chem 31:426-428
Mitchell A, Stevens G (2009) Life cycle assessment of closed loop MDF recycling: microrelease trial. WRAP-Waste and Resources Action Programme, Banbury, UK

Moezzipour B, Abdolkhani A, Doost-hoseini K et al (2018) Practical properties and formaldehyde emission of medium density fiberboards (MDFs) recycled by electrical method. Eur J Wood Prod 76:1287-1294. https://doi.org/10.1007/s00107-018-1291-2

Myers GC (1983) Relationship of fiber preparation and characteristics to performance of medium-density hardboards. For Prod J 33:43-51

Roffael E, Hüster H-G (2012) Complex chemical interactions on thermo hydrolytic degradation of urea formaldehyde resins (UFresins) in recycling UF-bonded boards. Eur J Wood Prod 70:401405. https://doi.org/10.1007/s00107-011-0574-7

Roffael E, Dix B, Behn C, Bär G (2009) Chemische Eigenschaften von TMP und CTMP, hergestellt aus Kiefernholz und UF-Harzgebundenen mitteldichten Faserplatten (MDF) - Chemical properties of TMP and CTMP prepared from pine wood and UF-bonded MDF. Eur J Wood Prod 67:113-115. https://doi.org/10.1007/ s00107-008-0269-x

Roffael E, Dix B, Behn C, Bär G (2010a) Mitverwendung von UFHarz-gebundenen Gebrauchtspan- und -faserplatten in der MDFHerstellung-Use of UF-bonded recycling particle- and fibreboards in MDF-production. Eur J Wood Prod 68:121-128. https:// doi.org/10.1007/s00107-009-0376-3

Roffael E, Dix B, Behn C, Bär G (2010b) Use of UF-bonded recycling particle- and fibreboards in MDF-production. Eur J Wood Prod 68:121-128. https://doi.org/10.1007/s00107-009-0376-3

Roffael E, Behn C, Schneider T, Krug D (2016) Bonding of recycled fibres with urea-formaldehyde resins. Int Wood Prod J 7:36-45. https://doi.org/10.1080/20426445.2015.1131918

Roffael E, Athanassiadou E, Mantanis G (2002) Recycling of particleand fiberboards using the extruder technique. In: Proceedings of the 2nd international conference on environmental protection in the wood industry. Göttingen, pp 56-65

Rowell RM, Youngquist JA, Mcnatt D (1991) Composites from Recycled Materials. In: Maloney TM (ed) Proceedings of the 25th International particleboard/composite materials symposium. Pullman, Washington, USA, pp 301-314

Sala CM, Robles E, Kowaluk G (2020) Influence of adding offcuts and trims with a recycling approach on the properties of high-density fibrous composites. Polymers 12:1327. https://doi.org/10.3390/ polym 12061327

Schoo A, Roffael E, Uhde M (2003) Mitteldichte Faserplatten (MDF) aus gebrauchten Oriented Strandboard (OSB) - MDF from recovered OSB. Holz Roh- Werkst 61:390-391. https://doi.org/10.1007/ s00107-003-0407-4

Thoemen H, Irle M, Sernek M (eds) (2010) Chapter 1: Wood-Based Panel Technology. In: Wood-based panels: an introduction for specialists. Brunel Univ. Press, London, pp 61-73

Wan H, Wang X-M, Barry A, Shen J (2014) Recycling wood composite panels: Characterizing recycled materials. BioResources 9:7554-7565

Wong ED, Zhang M, Wang Q et al (2000) Formation of the density profile and its effects on the properties of fiberboard. J Wood Sci 46:202-209

WPIF (2014) Panel Guide - Version 4. Wood Panel Industries Federation ISBN 978-1-909594-21-0

Ye XP, Julson J, Kuo M et al (2007) Properties of medium density fiberboards made from renewable biomass. Bioresour Technol 98:1077-1084. https://doi.org/10.1016/j.biortech.2006.04.022

Publisher's Note Springer Nature remains neutral with regard to jurisdictional claims in published maps and institutional affiliations. 